\title{
Careful Non-operative Management with Surveillance of Acute Appendicitis During COVID-19 Pandemic
}

\author{
Surender Verma ${ }^{1}$ (D) $\cdot$ Pradeep Garg $^{1} \cdot$ Anjali Verma $^{2} \cdot$ Vivek Sirohi $^{1}$ \\ Received: 14 July 2020 / Accepted: 29 September 2020 / Published online: 5 October 2020 \\ (C) Association of Surgeons of India 2020
}

Coronavirus disease (COVID-19) due to SARS-CoV-2 has caused major healthcare crisis globally. The countries who have suffered from pandemic are sharing their experience to limit the damage. Surgery is among the worst hit services by looking at the rapid surge of COVID-19 patients. Since the commencement of lockdown on 25 March 2020, only emergency surgical services are being provided, and there is a general push to manage surgical emergencies preferably by non-operative means because of safety issue in general anesthesia and surgical procedures especially laparoscopy due to risks of aerosol generation [1].

Acute appendicitis is one of the most common surgical emergency. Although some groups and randomized controlled trials have advocated conservative approach [2], in India operative intervention had remained the predominant strategy in appendicitis before the pandemic. This is due to the concern of high rates of failure with a conservative approach, increased hospital stay and lack in widespread availability of CT, and failure of majority of patients to have regular follow-up. We have studied how our surgical preferences have changed with regard to management of acute appendicitis over the last 100 days in a tertiary care teaching hospital.

We took details of cases of non-complicated acute appendicitis, their treatment, and outcome in last 100 days ( 25 March to 2 July 2020), and they are being compared with cases in last year (25 March to 2 July 2019). Informed consent was taken from all patients for publication of the data. Out of 91 patients during COVID pandemic, 63(69.2\%) underwent careful non-operative management with surveillance which included 35 out of 52 males $(67.3 \%)$ and 28 out of 39 females

Surender Verma

drsurn@gmail.com

1 Department of General Surgery, PGIMS, Rohtak, India

2 Department of Pediatrics, PGIMS, Rohtak, India
(71.6\%). Out of these 63 patients, 11 (6 males and 5 females) had to be operated later in view of appendicular abscess (7 patients) and increased rebound tenderness (4 patients). Among these, 6 had superficial wound dehiscence resulting in prolonged hospital stay, whereas 5 had normal course. Twenty-eight patients underwent surgery at the first go. Whereas out of 126 cases in 2019, 28 (22.2\%) cases underwent non-operative approach, and 2 of them had to undergo appendicectomy due to failure of treatment. The median length of stay in this approach was more than in those undergoing appendicectomy in the same period (5.2 vs 2.8 days).

We hereby advocate careful non-operative management with surveillance in non-complicated acute appendicitis in a pandemic situation so that it will not put burden on existing overloaded health system. Based on our clinical experience, clinical parameters which guided to early appendicectomy were no improvement in rebound tenderness and non-significant decrease in TLC within $48 \mathrm{~h}$. In concordance with our study, Collard et al. recommended medical treatment as a possible alternative that is immediately applicable to care for the non-complicated acute appendicitis patients when there is a risk of spread of infection through aerosols. Reduction of the afflux of patients, even if small, should not be under-estimated because the stakes for patients requiring in-hospital care for a severe form of COVID-19 infection are vital [3].

In a survey based study in Ireland, a maximum of surgeons (74\%) have modified their practice to a predominant conservative approach, but $83 \%$ wanted to revert back to operative management after COVID-19 crisis. Even $63 \%$ of patients in conservative care group wanted to choose up-front appendicectomy if they could decide again, and $45 \%$ are interested in interval appendicectomy [4].

Surgeons in the UK also believe that conservative management should not be undertaken in patients who would normally undergo appendicectomy. They advocate early open appendicectomy over laparoscopy in patients with clinical appendicitis even during the pandemic [5]. 
Even though this approach may deprive the patient from standard operative intervention, still we propose this therapeutic alternative to be applied in a situation like this, and even after this crisis, this practice may be considered, thus avoiding operation in significant number of patients. Furthermore, studies are required to fill the gap to deliver surgical services safely and effectively during COVID 19 pandemic and afterward.

Acknowledgments To all the patients of appendicitis who had undergone treatment in our institute.

\section{References}

1. Brat GA, Hersey SP, Chhabra K, Gupta A, Scott J (2020) Protecting surgical teams during the COVID-19 outbreak: a narrative review and clinical considerations. Ann Surg. Publish Ahead of Print. https://doi.org/10.1097/SLA.0000000000003926
2. Vons C, Barry C, Maitre S, Pautrat K, Leconte M, Costaglioli B, Karoui M, Alves A, Dousset B, Valleur P, Falissard B, Franco D (2011) Amoxicillin plus clavulanic acid versus appendectomy for treatment of acute uncomplicated appendicitis: an open-label, noninferiority, randomized controlled trial. Lancet 377:1573-1579

3. Collard M, Lakkis Z, Loriau J, Mege D, Sabbagh C, Lefevre JH, Maggiori L (2020) Antibiotics alone as an alternative to appendectomy for uncomplicated acute appendicitis in adults: changes in treatment modalities related to the COVID-19 health crisis. J Visc Surg 157:S33-S43

4. Kelly ME, Murphy E, Bolger JC, Cahill RA (2020) COVID-19 and the treatment of acute appendicitis in Ireland: a new era or short-term pivot? Color Dis 22:648-649. https://doi.org/10.1111/codi.15141

5. Scott C, Lambert A (2020) Managing appendicitis during the COVID -19 pandemic in the UK. Br J Surg 107:e271. https://doi. org/10.1002/bjs. 11752

Publisher's Note Springer Nature remains neutral with regard to jurisdictional claims in published maps and institutional affiliations. 